\title{
ESTATUS SOCIAL Y PATRONES DE PATOLOGÍA ORAL EN PESCADORES-AGRICULTORES TARDÍOS DEL CEMENTERIO LOS PINOS (COSTA CENTRAL DEL PERÚ)
}

\author{
SOCIAL STATUS AND ORAL PATHOLOGY IN LATER \\ FISHER-AGRICULTURALISTS FROM LOS PINOS CEMETERY \\ (CENTRAL PERUVIAN COAST)
}

\author{
Luis Pezo-Lanfranco ${ }^{1}$ y Sabine Eggers ${ }^{1}$
}

\begin{abstract}
El presente trabajo examina variaciones dietéticas asociadas a diferencias de estatus al interior de comunidades jerarquizadas utilizando indicadores de patología oral. En los Andes Centrales, a pesar de la existencia comprobada de profundas divisiones sociales, la etnohistoria sugiere pocas diferencias dietéticas durante periodos tardíos, pero los datos bioarqueológicos que sustenten esta afirmación son escasos. Se analizaron 145 individuos exhumados del cementerio Los Pinos del valle de Huaura, costa central peruana (ca. 1200-1300 d.C.). Este conjunto de individuos fue clasificado en tres grupos de estatus social de acuerdo con la riqueza en ofrendas de los entierros. En dicha muestra se estudiaron 14 indicadores de patología oral. Los resultados muestran que todos los individuos de Los Pinos, independientemente de su grupo de estatus, estaban expuestos a una dieta considerablemente cariogénica y exhiben un patrón de lesiones común en el que predominan caries oclusales y una altísima proporción de caries cervicales (que parece estar estrechamente asociada al consumo de chicha), remanentes radiculares y abundantes pérdidas dentales en vida (con una mayor propensión en mujeres). Los datos de patología oral sugieren que el estatus social no condicionó el consumo diferenciado de carbohidratos y confirman el carácter extendido del hábito de coqueo en todos los grupos sociales, con un ligero predominio en individuos masculinos de estatus superior.
\end{abstract}

Palabras claves: patología oral, paleodieta, Intermedio Tardío, Señorío Huaura-Chancay.

In this paper we examine dietary contrasts associated with differences in status within hierarchical communities using oral pathology markers. In the Central Andes, despite the demonstrated existence of deep social divisions, ethno-history suggests few differences in diet between groups during later prehistoric periods, but this claim has little bioarchaeological support. A sample of 145 individuals from the cemetery of Los Pinos of the Huaura Valley, in the central Peruvian coast (ca. 1200-1300 AD), was classified into three groups according to social status, number of offerings and wealth of burials. Then we registered 14 markers of oral pathology. The results show that all individuals in Los Pinos, regardless of their social status group, were exposed to a significant cariogenic diet and exhibited a common pattern of lesions: occlusal caries, high proportion of cervical caries (which appears to be closely associated to consumption of maize beer), gross caries and root remains and high frequencies of ante mortem tooth loss (with higher tendency in females). Oral pathology data suggests that social status did not produce differentiated consumption of carbohydrates and confirms the widespread coca leaf chewing habit in all groups, with a slight predominance in male individuals of higher status.

Key words: Oral pathology, paleodiet, Late Intermediate Period, Señorío Huaura-Chancay.

Estudios bioarqueológicos han constatado diferencias en los perfiles de salud oral de los individuos según su localización en escalas de clasificación social (Boyce et al. 2010; Pattussi et al. 2001; Sakashita et al. 1997; Walker y Hewlett 1990). Esta relación, que está asociada a los diferentes modos de vida y principalmente a diferencias de acceso a determinados tipos de alimentos, ha sido poco estudiada en los Andes Centrales, donde a pesar de la existencia comprobada de profundas divisiones sociales en épocas prehispánicas tardías, se sostiene la idea de poblaciones bien alimentadas al momento del contacto (Antúnez de Mayolo 1981; Espinoza 1987; Rostworowski 2004).

Según datos etnohistóricos y arqueológicos, durante el Intermedio Tardío (PIT 1000-1470 d.C.), un periodo de reorganización política y fortalecimiento de las identidades regionales, el territorio andino estaba ocupado por sociedades complejas altamente estratificadas, divididas en una clase dirigente, "los señores" (que podían ser de varias categorías y rangos), un segundo estrato

1 Departamento de Genética e Biologia Evolutiva, Instituto de Biociências, Universidade de São Paulo, Brasil. luispezolanfranco@usp.br; saeggers@usp.br 
constituido por labradores y artesanos y, por último, los sirvientes, gente que por diversos motivos había sido despojada de todos sus derechos (Espinoza 1987, 2008; Parsons y Hastings 1988; Rostworowski 1993, 2004).

En la costa central del Perú estas unidades políticas, que abarcaban uno o dos valles, han sido definidas como estados, reinos, señoríos, curacazgos o confederaciones, según cada autor (Dillehay 1987; Espinoza 1987; Rostworowski 1993; Silva 1996; Vallejo 2008a), y formaban parte de un contexto de integración socioeconómica interregional, con contactos permanentes de corta y larga distancia, alta densidad poblacional y un avanzado desarrollo de los sistemas productivos (Espinoza 2008; Parsons y Hastings 1988).

En la costa de los Andes centrales la dieta dependía de un sistema de producción principalmente agrícola (con predominio de maíz, leguminosas y tubérculos según la estación, Williams y Katzenberg 2012), complementada con peces y moluscos endémicos y productos provenientes del comercio (tubérculos altoandinos, plantas amazónicas), y en sus formas de consumo concurren variadas técnicas ancestrales de preparación y conservación. Sistemas de complementariedad ecológica y diversas estrategias de apropiación de los recursos naturales garantizaban una dieta variada en este escenario especialmente árido (Dillehay 1987; Murra 1972). Algunos autores han calificado esta dieta como "homogénea, balanceada y saludable" (Antúnez de Mayolo 1981:27; León 2013; ver Horkheimer 1973 para una argumentación contraria).

Según las fuentes etnohistóricas, entre las estrategias de control y cohesión social utilizadas por las elites estaban la redistribución asimétrica y la dádiva de algunos productos específicos a cambio de tributo y trabajo. Entre estos productos figuran la hoja de coca, planta muy apreciada por sus cualidades estimulantes y medicinales (Bradley 2013:25), que era destinada a rituales y al hábito de masticación (coqueo), y la chicha, bebida fermentada que era ofrecida por los señores al pueblo, que la consumía regularmente durante el trabajo y el descanso (Espinoza 1987:108; Moore 1989; Rostworowski 2004).

Los historiadores han recreado un escenario donde los señores, cuyo capital político y poder estaba basado en la disponibilidad de fuerza de trabajo, invertían en su pueblo al que debían garantizar cuidados y alimentación. Así, aunque los datos bioarqueológicos son escasos, las fuentes etnohistóricas aseveran que el pueblo estaba tan bien alimentado como la elite (Antúnez de Mayolo 1981:138).

A partir de estas afirmaciones surgen aquí algunas preguntas a ser respondidas: ¿Existían diferencias dietéticas asociadas a las diversas categorías de estatus social al interior de estas comunidades? ¿Existen marcadores biológicos que reflejen estas potenciales variaciones? Considerando que las lesiones orales (caries, enfermedad periodontal, entre otras) son buenos indicadores del consumo de determinadas dietas, se espera observar diferencias en los patrones de patología oral entre individuos de diferente posición social. Hipotéticamente, individuos de estatus social más alto consumen más proteínas que los de menor estatus, que a su vez consumen más carbohidratos. Por tanto, los individuos de menor estatus deben mostrar más lesiones orales. Sin embargo, en el caso específico de los Andes Centrales concurren una serie de factores culturales, asociados al valor ritual y prestigio económico de plantas como el maíz o la coca, que podrían modificar esta relación (Hastorf y Johannessen 1993; Indirati y Buikstra 2001).

Para aportar a la discusión de este tema se presenta un análisis exploratorio de patología oral en una muestra representativa de individuos de una sociedad compleja tardía de la costa peruana, de la que se tienen abundantes referencias etnohistóricas y arqueológicas.

\section{El Sitio Arqueológico Los Pinos}

El sitio arqueológico Los Pinos (11 ${ }^{\circ} 07^{\prime} 13^{\prime \prime}$ S$77^{\circ} 35^{\prime} 32^{\prime \prime} \mathrm{W}$ ) se ubica a $2,5 \mathrm{~km}$ del puerto de Huacho, sobre la margen sur del valle bajo del río Huaura, costa central del Perú (Figura 1). Se trata de un cementerio asignado al PIT, localizado en las proximidades del sitio Cerro Colorado, el principal asentamiento del valle bajo y capital de lo que hoy se conoce como el "Señorío Huaura-Chancay", uno de los más prestigiosos y ricos del período (Cárdenas 1977; Krzanowski 1991; Rostworowski 1978, 2004; Ruiz 1981).

El cementerio Los Pinos subyace a un asentamiento moderno y fue excavado como parte de un proyecto de rescate arqueológico. En 2007 se exhumaron 437 contextos funerarios, que contenían aproximadamente 526 individuos (Gonzáles 2007). En su patrón funerario, característico de la sociedad 


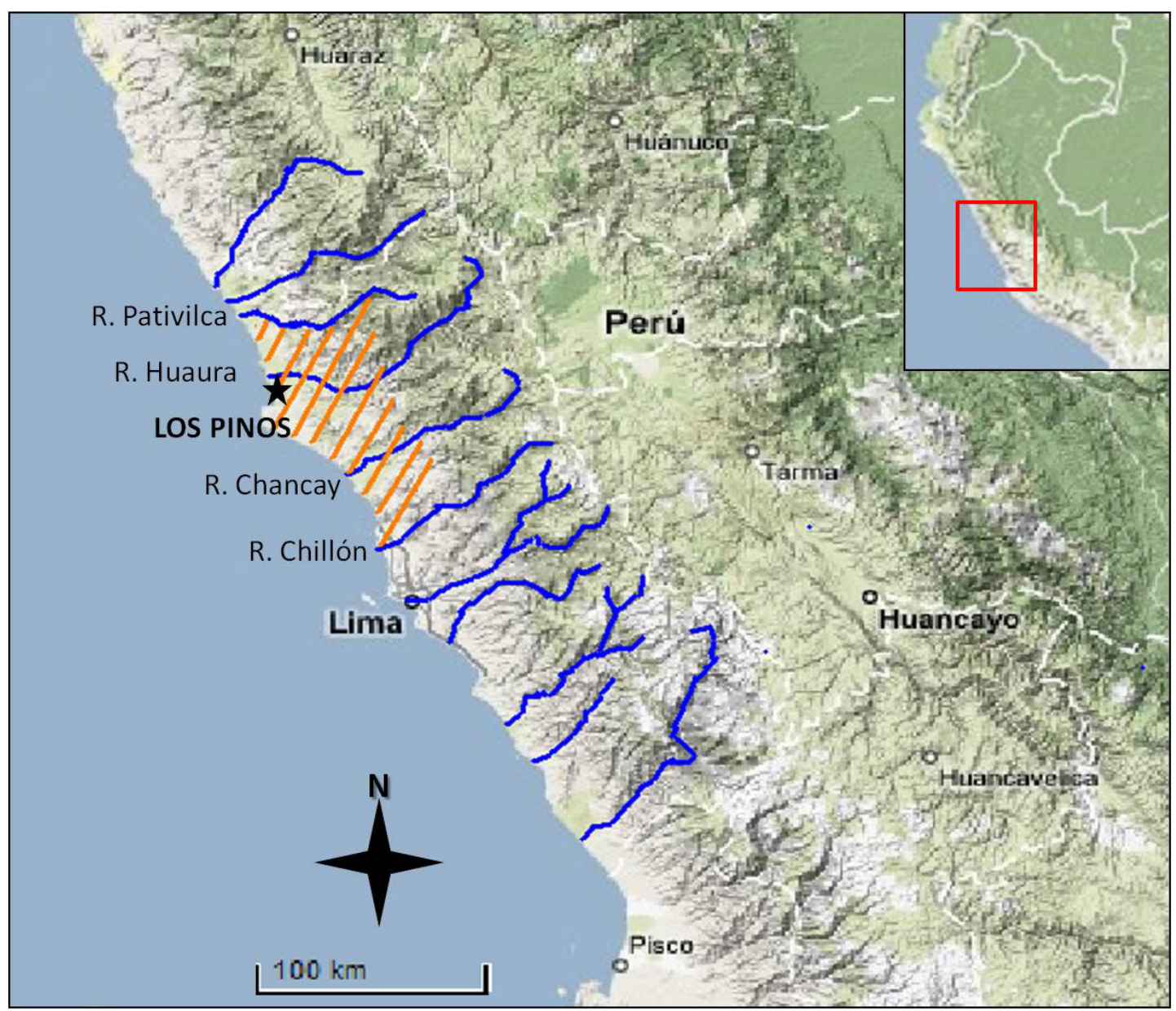

Figura 1. Localización del sitio Los Pinos en el territorio del Señorío Huaura-Chancay (1000-1470 d.C.), costa central del Perú (modificado de Google maps 2008).

Location of Los Pinos site in the territory of the Señorío Huaura-Chancay (1000-1470 AD), in the central Peruvian coast (modified from Google maps 2008).

Huaura-Chancay (Cornejo 1991; Ruiz 1981:137), los individuos están depositados en fosas de profundidad variable (1-3 metros), en posición sedente, flexionada y acompañados de vasijas de cerámica, figurinas de arcilla de estilo Chancay y ocasionales adornos de diversos materiales (Gonzáles 2007).

Algunos individuos estaban envueltos en fardos funerarios (momificados o semimomificados), pero la mayoría no estaba en fardos y se hallaban totalmente esqueletizados. En Los Pinos se ubicaron entierros "complejos", algunos de ellos múltiples y bastante elaborados, con gran cantidad de artefactos (hasta 60 elementos) y cámaras funerarias de dos niveles, mientras que otros son relativamente sencillos y sin ofrendas. La datación relativa de los contextos funerarios de Los Pinos (basada en cerámica diagnóstica y estratigrafía), sugiere su pertenencia a la época media del PIT (ca. 1200-1300 d.C.) (Gonzáles 2007; Vallejo 2008b).

En general, los contextos funerarios HuauraChancay confirman claras diferencias sociales y división del trabajo entre individuos. En algunas sepulturas de individuos masculinos suelen encontrarse herramientas agrícolas y sacos de tela con semillas de varios tipos, armas, instrumentos musicales, artefactos de metal. Los individuos femeninos presentan objetos relacionados con el oficio textil como telares, instrumentos para hilar, agujas, colorantes y algodón (Cornejo 1991; Ruiz 1991; Vallejo 2008b).

En Los Pinos, las vasijas asociadas a los individuos (entre las que abundan las ollas globulares, 
cántaros, cuencos, platos, vasos y mates usados como recipientes) contenían restos de alimentos muy bien conservados que indican una dieta basada principalmente en el consumo de maíz, tubérculos de varias especies, cucurbitáceas, maní, peces y moluscos de la región. Muchas de las vasijas excavadas contenían sedimentos compatibles con almidón de chicha, pero aun no se han realizado estudios microscópicos para determinar a qué especie corresponden. Finalmente, la hoja de coca ha sido reportada en los contextos locales y en otros inventarios del valle de Huaura de esta época (Cárdenas 1977; González 2007; Ruiz 1981).

\section{Materiales y Métodos}

De los 526 individuos excavados en Los Pinos se analizaron 145. Considerando el buen estado de conservación de los restos óseos, se seleccionaron individuos con cráneos íntegros y maxilares con denticiones casi completas ( $>$ de $80 \%$ ).

Para responder a la pregunta de si había diferencias dietéticas al interior de esta sociedad, a partir de una evaluación previa de la riqueza de los entierros respecto del número de ofrendas e inversión de energía en su elaboración, se hizo una clasificación arbitraria en tres grupos de Estatus Social Relativo (Superior, Medio e Inferior) siguiendo referencias anteriores (Cornejo 1991).

Se incluyeron dentro de la categoría de Estatus Inferior aquellos individuos enterrados en fosas sencillas, con dos o menos artefactos asociados (Figura 2a). Los individuos con tres y ocho ofrendas fueron incluidos en la categoría de Estatus Medio (Figura 2b). Individuos correspondientes a entierros complejos (con fardos más elaborados, mayor cantidad de cubiertas textiles, estructuras complementarias y varios pisos de ofrendas) y con más de ocho artefactos y objetos suntuarios (láminas de metal, algunas de oro o aleaciones, figurinas y elementos exóticos, suntuarios o de valor simbólico), fueron clasificados en la categoría de Estatus Superior (Figura 2c).

La determinación del sexo se basó en criterios de morfología pélvica y craneal (Buikstra y Ubelaker 1994:15). La edad en adultos fue estimada mediante morfología de la sínfisis púbica (Brooks y Suchey 1990) y cierre de suturas craneales (Meindl y Lovejoy 1985). En subadultos (individuos menores de 12 años), la edad fue estimada mediante observación de cierre de centros secundarios de osificación, desarrollo vertebral y secuencia de desarrollo de la dentición (Sheuer y Black 2000). La distribución de la muestra por sexo y edad puede ser observada en la Tabla 1.

Para el análisis de patología oral se utilizaron 14 indicadores: frecuencia y prevalencia de caries, frecuencia y prevalencia de dientes perdidos antemortem (AMTL-antemortem tooth loss), frecuencia de caries por tipo, media de dientes cariados por individuo y media de lesiones de caries (cuando un diente tiene más de una caries), prevalencia de enfermedad periodontal (incluidos índices de cálculo dental y reabsorción alveolar), prevalencia de lesiones periapicales e hipoplasias de esmalte, e índice de desgaste oclusal. Por último se utilizó el método de
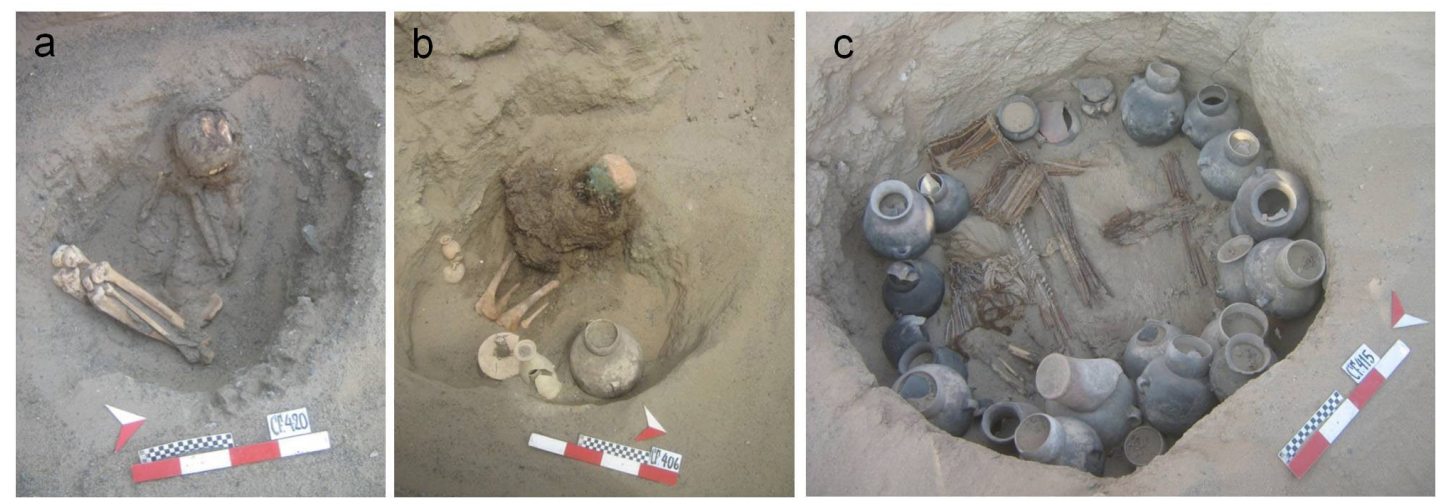

Figura 2. Clasificación de los contextos funerarios de Los Pinos: (a) Estatus Inferior, $\leq 2$ ofrendas, tumbas simples; (b) Estatus Medio, 3-8 ofrendas, tumbas poco elaboradas; (c) Estatus Superior, $\geq 9$ ofrendas y otros abalorios, tumbas complejas, acompañantes (fotografías del Proyecto de Rescate Arqueológico Los Pinos de Huacho).

Classification of funerary contexts from Los Pinos: (a) Lower Status, $\leq 2$ offerings, simple burials; (b) Middle Status, 3-8 offerings, less complex burials; (c) Higher Status, $\geq 9$ offerings and other ornaments, complex burials (photos by Proyecto de Rescate Arqueológico Los Pinos de Huacho). 
Indriati y Buikstra (2001) para identificar individuos con hábito de masticación de hoja de coca.

Las "frecuencias" están referidas al número de dientes o alvéolos afectados por una patología en un individuo, la frecuencia reportada aquí es la media de los valores de los individuos de cada grupo. La "prevalencia" es el número de individuos afectados por determinada condición en cada grupo (Pezo-Lanfranco y Eggers 2012).

Con el objetivo de evaluar diferencias dietéticas más finas, se aplicó un método que da mayor énfasis a las características de las lesiones. Teóricamente, la coexistencia y recurrencia de determinados tipos de caries permiten la identificación de dietas más o menos cariogénicas. Dietas más cariogénicas, es decir, más ricas en carbohidratos fermentables y/o refinados consumidos con mayor frecuencia, producen, además de lesiones de caries en superficies más proclives (superficies oclusales, surcos y fisuras), lesiones en zonas no retentivas de los dientes (Badet y Thebaud 2008; Gibbons et al. 1974; Hillson 2001; Kleinberg 2002; Rugg-Gunn y Hackett 1993).
En este trabajo se registraron nueve categorías o "tipos de caries" (Figura 3): caries oclusales, caries de pozos y fisuras vestibulares o cingulares, caries extra-oclusales (que incluyen caries de superficies dentales lisas mesial/distal y bucal/ lingual, caries interproximales y caries cervicales o de límite esmalte-cemento), caries asociadas a desgaste (que vale la pena diferenciar, pues tiene más relación con la abrasividad de la dieta que con su cariogenicidad, Lukacs 1996) y remanentes radiculares, que normalmente son el resultado final del proceso de caries de cualquier origen (Hillson 2001; Pezo-Lanfranco y Eggers 2010:81). Cuando se presentó más de una caries en un diente se registró el tipo asociado a mayor cariogenicidad de la dieta. Por ejemplo, un diente con dos caries: oclusal y interproximal, fue clasificado dentro de la categoría 4 (caries interproximal). Para complementar la información se reporta la media de dientes cariados y la media de lesiones de caries para cada grupo.

El índice de cálculo dental fue categorizado como: (1) cálculo supra-gingival escaso (manchas

Tabla 1. Estructura demográfica de la muestra de Los Pinos según estatus social. Demographic structure of Los Pinos sample by social status.

\begin{tabular}{|c|c|c|c|c|c|c|}
\hline \multirow{2}{*}{ Estatus } & \multirow{2}{*}{ Edad } & \multirow{2}{*}{$\mathrm{n}$} & \multirow{2}{*}{$\%$} & \multicolumn{3}{|c|}{ Sexo } \\
\hline & & & & M & $\mathrm{F}$ & Ind \\
\hline \multirow[t]{6}{*}{ Superior } & SA & 6 & 24,00 & 0 & 0 & 6 \\
\hline & $\mathrm{Ad}$ & 0 & 0,00 & 0 & 0 & 0 \\
\hline & $\mathrm{AJ}$ & 4 & 16,00 & 1 & 2 & 1 \\
\hline & $\mathrm{AM}$ & 13 & 52,00 & 8 & 4 & 1 \\
\hline & $\mathrm{AV}$ & 2 & 8,00 & 0 & 2 & 0 \\
\hline & Sub-Total & 25 & 100,00 & 9 & 8 & 8 \\
\hline \multirow[t]{6}{*}{ Medio } & SA & 3 & 4,62 & 0 & 0 & 3 \\
\hline & $\mathrm{Ad}$ & 1 & 1,54 & 1 & 0 & 0 \\
\hline & AJ & 14 & 21,54 & 7 & 7 & 0 \\
\hline & $\mathrm{AM}$ & 37 & 56,92 & 12 & 23 & 2 \\
\hline & $\mathrm{AV}$ & 10 & 15,38 & 0 & 10 & 0 \\
\hline & Sub-Total & 65 & 100,00 & 20 & 40 & 5 \\
\hline \multirow[t]{7}{*}{ Inferior } & SA & 10 & 18,18 & 0 & 0 & 10 \\
\hline & Ad & 7 & 12,73 & 1 & 4 & 2 \\
\hline & AJ & 9 & 16,36 & 6 & 3 & 0 \\
\hline & $\mathrm{AM}$ & 27 & 42,09 & 11 & 13 & 3 \\
\hline & AV & 2 & 3,64 & 1 & 1 & 0 \\
\hline & Sub-Total & 55 & 100,00 & 19 & 21 & 15 \\
\hline & Total & 145 & 100,00 & 48 & 69 & 28 \\
\hline
\end{tabular}

$\mathrm{SA}=$ Subadultos, individuos menores de 12 años; Ad = Adolescentes, 12-19 años; AJ = Adulto Joven, 20-29 años; AM = Adulto Medio, 30-49 años; AV = Adulto Viejo > 50 años; Ind = Indeterminado. 

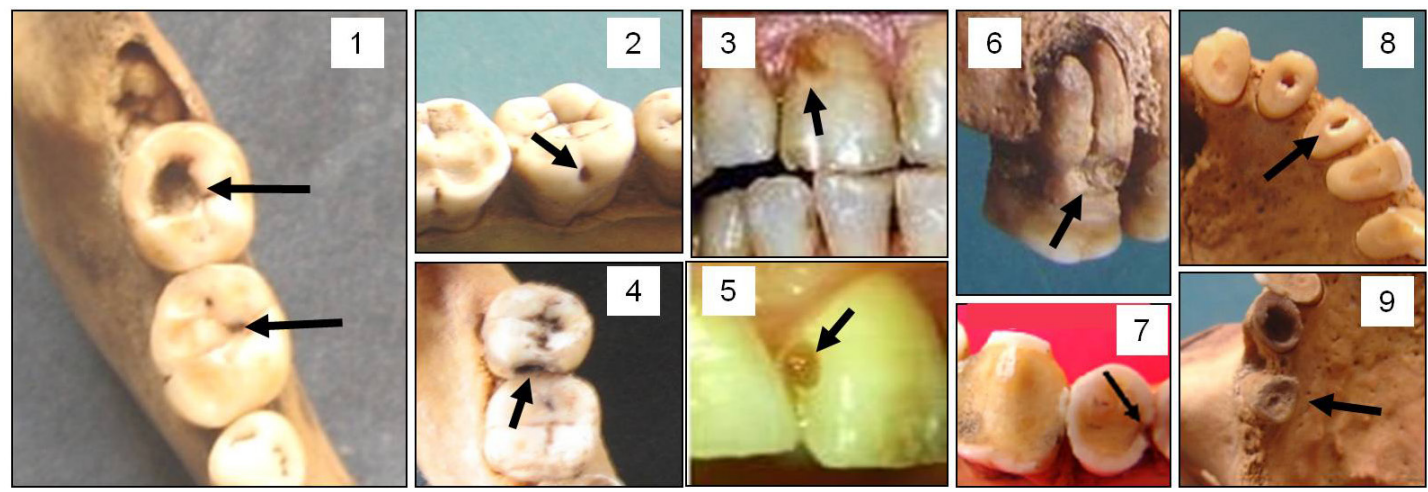

Figura 3. Tipos de caries registrados en esta investigación: (1). Oclusal; (2). Caries de surco o pozo vestibular o cíngulo; (3). Superficie lisa vestibular o lingual; (4). Interproximal; (5). Superficie lisa mesial o distal; (6). Cervical y/o de límite esmaltecemento; (7). Desgaste oclusal, fractura de cresta de esmalte y caries; (8). Desgaste oclusal, exposición pulpar y caries de dentina; (9). Remanentes radiculares.

Caries types recorded in this work: (1). Occlusal; (2). Pit caries; (3). Smooth surface buccal or lingual; (4). Approximal; (5). Smooth surface mesial or distal; (6). Cervical or CEJ caries; (7). Occlusal attrition, enamel edge chipping and caries; (8). Occlusal attrition, pulp exposure, and dentine caries; (9). Gross-gross caries or root remains.

o líneas calcificadas $<1$ mm de espesor); (2) cálculo supra-gingival abundante (>1 mm de espesor); (3) cálculo infra-gingival (por debajo del límite esmalte-cemento) de cualquier espesor. El índice de reabsorción alveolar fue registrado según las siguientes categorías: (1) leve: entre $2 \mathrm{~mm}$ y menos de $1 / 4$ de la longitud de la raíz dental; (2) moderada: aproximadamente entre 1/4 y la mitad de la longitud radicular; (3) severa: más de la mitad de la longitud radicular (Pezo-Lanfranco 2010). Para registrar ambos indicadores se observaron las superficies lingual y bucal, calculándose una media por diente, una media por individuo (índice individual) y una media interindividual (índice grupal). Individuos con índice de reabsorción alveolar $>1$ fueron considerados como afectados por periodontitis (un cuadro clínico inflamatorio que implica pérdida de soporte dental).

El patrón de masticador de coca básicamente consiste en una reabsorción alveolar en forma de $\mathrm{V}$ en la zona molar ( $>3 \mathrm{~mm}$ ), lugar donde se coloca el bolo de coca, caries cervicales en el sector vestibular de molares y premolares, y altos índices de AMTL de molares (Indriati y Buikstra 2001:247).

El desgaste dental fue registrado con el Índice de Molnar (1971), que usa una escala ordinal de 1 a 8 para cuantificar el desgaste oclusal, discriminando incisivos, premolares y molares (Pezo-Lanfranco 2010:90-93). El índice individual es la media de los valores de todos los dientes presentes. El índice grupal es la media de los índices individuales.
A los efectos de discriminar patrones de patología oral asociados a cada categoría de estatus se siguieron tres pasos analíticos: (1) caracterización de los perfiles de patología oral de los tres grupos; (2) comparaciones intragrupales según sexo (individuos masculinos versus femeninos del mismo grupo); (3) comparaciones intergrupales por grupo de estatus según sexo (individuos masculinos de los tres grupos, por un lado, e individuos femeninos de los tres grupos, por otro). Para la estadística descriptiva e inferencial (prueba $t$, ANOVA, Test de MannWhitney, Test de Kruskal Wallis, Chi cuadrado y Test Exacto de Fisher, a un nivel de significancia de $p<0,05)$ se utilizó el programa SPSS 18.0.

\section{Resultados y Discusión}

En los 145 individuos se examinaron 4.317 alvéolos y 3.435 dientes. Las frecuencias de dientes sanos, perdidos antemortem (AMTL), perdidos postmortem (PMTL, presentados apenas como referencia al estado de conservación de las muestras), dientes cariados y su clasificación por "tipos", se presentan en la Tabla 2.

\section{Frecuencia de caries y AMTL}

La frecuencia de dientes cariados muestra proporciones relativamente similares entre grupos de estatus, sin diferencias significativas (Test Kruskal-Wallis $\left.X^{2}=2,191 p=0,334\right)$. En las 


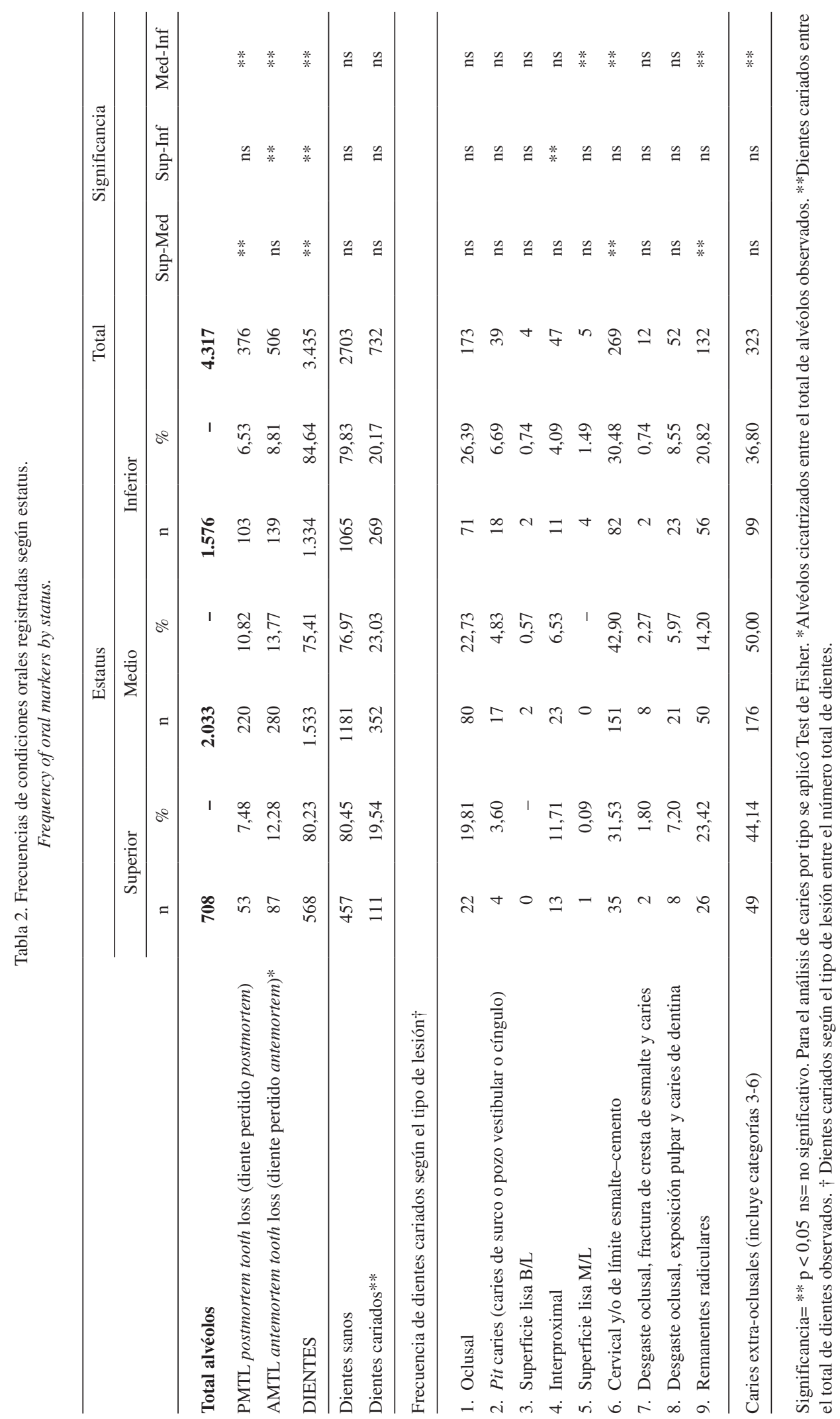


comparaciones intragrupo por sexo (Tablas 3 y 4) solo se observan diferencias estadísticamente significativas entre los individuos masculinos $(28,69 \%)$ y femeninos $(68,75 \%)$ de Estatus Medio $\left(X^{2}=112,7303 p=0,0000\right)$.

En las comparaciones intergrupo, los individuos femeninos de todos los grupos tienen más caries que los individuos masculinos. La baja frecuencia de caries de los individuos masculinos de Estatus Medio y la alta frecuencia observada de los individuos femeninos de este mismo grupo son estadísticamente significativas al ser comparadas con sus homólogos de Estatus Superior e Inferior. Los subadultos en general están poco afectados, pero hay diferencias estadísticamente significativas entre grupos. Los subadultos de Estatus Inferior tienen más caries que sus pares de Estatus Superior $\left(X^{2}=5.1131 p=0,0237\right.$ Fisher $=0,0218)$ y Estatus Medio $\left(X^{2}=10.4055\right.$ $p=0,0012$ Fisher=0,0016), lo que sugiere mayor exposición a dietas más cariogénicas.

Tabla 3. Dientes cariados y AMTL por sexo según estatus.

Carious teeth and AMTL by sex and status.

\begin{tabular}{|c|c|c|c|c|c|c|}
\hline Estatus & Sexo & $\mathrm{N}$ & Dientes cariados & $\%$ & AMTL & $\%$ \\
\hline \multirow{5}{*}{ Superior } & M & 9 & 50 & 45,05 & 29 & 33,33 \\
\hline & $\mathrm{F}$ & 8 & 46 & 41,44 & 53 & 60,92 \\
\hline & Ind & 2 & 15 & 13,51 & 5 & 5,75 \\
\hline & Subadultos* & 6 & 0 & 0,00 & 0 & 0,00 \\
\hline & Total & 25 & 111 & 100,00 & 87 & 100,00 \\
\hline \multirow{5}{*}{ Medio } & M & 20 & 101 & 28,69 & 61 & 21,79 \\
\hline & $\mathrm{F}$ & 40 & 242 & 68,75 & 205 & 73,21 \\
\hline & Ind & 2 & 7 & 1,99 & 14 & 5,00 \\
\hline & Subadultos & 3 & 2 & 0,57 & 0 & 0,00 \\
\hline & Total & 65 & 352 & 100,00 & 280 & 100,00 \\
\hline \multirow{5}{*}{ Inferior } & M & 19 & 114 & 42,38 & 56 & 40,29 \\
\hline & $\mathrm{F}$ & 21 & 128 & 47,58 & 69 & 49,64 \\
\hline & Ind & 5 & 15 & 5,58 & 14 & 10,07 \\
\hline & Subadultos & 10 & 12 & 4,46 & 0 & 0,00 \\
\hline & Total & 55 & 269 & 100,00 & 139 & 100,00 \\
\hline
\end{tabular}

* La categoría Subadultos incluye individuos menores de 12 años.

Tabla 4. Significancia estadística para frecuencias de caries y AMTL entre grupos*. Statistic significance for caries and AMTL frequencies among groups.

\begin{tabular}{|c|c|c|c|c|c|c|c|c|c|}
\hline \multirow[b]{3}{*}{ Caries } & \multicolumn{3}{|c|}{ Comparaciones Intragrupo } & \multicolumn{6}{|c|}{ Comparaciones Intergrupo } \\
\hline & Superior & Medio & Inferior & \multicolumn{3}{|c|}{$\hat{\sigma}$} & \multicolumn{3}{|c|}{ 우 } \\
\hline & $\hat{\sigma}$ & q & $\hat{\sigma}$ & Sup-Med & Sup-Inf & Med-Inf & Sup-Med & Sup-Inf & Med-Inf \\
\hline $\mathrm{X}^{2}$ & 0,3856 & 112.7303 & 1.4721 & 10.3881 & 0,2276 & 12.4187 & 26.3689 & 1.1942 & 27.8598 \\
\hline $\mathrm{p}$ & 0,5346 & 0,0000 & 0,2250 & 0,0013 & 0,6333 & 0,0004 & 0,0000 & 0,2745 & 0,0000 \\
\hline AMTL & $\hat{\sigma}$ & $\hat{\sigma}$ & $\hat{\sigma}$ & Sup-Med & Sup-Inf & Med-Inf & Sup-Med & Sup-Inf & Med-Inf \\
\hline $\mathrm{X}^{2}$ & 13.2853 & 148.4855 & 2.4556 & 4.7820 & 1.1029 & 15.7992 & 4.8055 & 2.7404 & 22.8105 \\
\hline $\mathrm{p}$ & 0,0003 & 0,0000 & 0,1170 & 0,0288 & 0,2936 & 0,0001 & 0,0284 & 0,0978 & 0,0000 \\
\hline
\end{tabular}

* Se consideraron solamente los individuos adultos de sexo determinado. 
Para la frecuencia de AMTL tampoco hay diferencias significativas entre los tres grupos de estatus como un todo (Test Kruskal-Wallis $X^{2}=4.222$ $p=0,121)$. Sin embargo, en las comparaciones intragrupo se observa que los individuos femeninos tienen más AMTL que los individuos masculinos en los tres grupos, con significancia estadística entre individuos de Estatus Superior y Estatus Medio (Tablas 3 y 4). En la comparación intergrupal, individuos masculinos de Estatus Medio tienen una frecuencia muy baja de AMTL $(21,79 \%)$, estadísticamente significativa frente a sus pares de Estatus Superior e Inferior. Los individuos femeninos de Estatus Medio (73,21\%) presentan frecuencias significativamente mayores de AMTL cuando son comparados con individuos femeninos de Estatus Superior e Inferior. No se observaron AMTL en subadultos.

Las diferencias observadas en los individuos de Estatus Medio son muy sugerentes. En individuos masculinos se nota un mejor estado de salud oral, probablemente asociado con menos consumo de carbohidratos cariogénicos, mientras individuos femeninos muestran más AMTL y mayor exposición a factores cariogénicos. No obstante, se trata de una muestra relativamente más joven y esa podría ser otra explicación a lo observado, considerando que estamos frente a procesos patológicos dependientes de la edad.

Las medias de dientes cariados y de lesiones de caries por individuo, observadas solo en adultos con sexo determinado (Tabla 5), confirman una mayor experiencia de caries en individuos femeninos en los tres grupos de estatus. En el análisis intergrupo en general hay una estrecha semejanza entre los tres grupos, con medias ligeramente mayores en individuos de Estatus Bajo. Utilizando Test $t$ no se detectaron diferencias significativas en ningún caso.

\section{Análisis de cariogenicidad: tipos de caries}

Carbohidratos más dulces o procesados ofrecen el substrato ideal para la multiplicación de determinadas colonias de bacterias con alto potencial cariogénico (Streptococcus del grupo mutans, Lactobacillus, Actinomyces, Veillonella, entre otras, responsables de alterar el equilibrio ácido-base intraoral) en superficies específicas del diente (Badet y Thebaud 2008; Brown et al. 1986; Kleinberg 2002; Love y Jenkinson 2002; Seif y Bóveda 1997). Modelos experimentales sugieren que principalmente la sacarosa, sacarosa con almidón, fructosa y dextrosa, estimulan la producción de lesiones de superficies lisas y cervicales, mientras que un mayor consumo de maltosa y maltodextrinas contenidas en almidones simples produce preferencialmente caries cervicales, y muy raramente caries de superficie lisa (Frostell et al. 1967; Lingström et al. 2000; Ribeiro et al. 2005).

Los tres grupos de estatus están afectados por elevadas frecuencias de caries oclusales, caries cervicales y remanentes radiculares. Las altas frecuencias de caries cervicales de individuos de Estatus Medio (43,06\%) y las bajas frecuencias de remanentes radiculares de individuos de Estatus Medio (14,16\%) son estadísticamente significativas (Tabla 2).

Algunos tipos de caries extra-oclusales son más comunes en determinados grupos. Las caries interproximales aparecen más frecuentemente en individuos de Estatus Superior $(11,71 \%)$ y las

Tabla 5. Media de dientes cariados y caries en boca por sexo, según estatus*. Mean of carious teeth and carious lesions by sex and status.

\begin{tabular}{|c|c|c|c|c|c|c|c|c|c|c|}
\hline \multirow{2}{*}{ Sexo } & \multirow{2}{*}{ Estatus } & \multicolumn{3}{|c|}{ Superior } & \multicolumn{3}{|c|}{ Medio } & \multicolumn{3}{|c|}{ Inferior } \\
\hline & & $\mathrm{N}$ & Media & ds & $\mathrm{N}$ & Media & ds & $\mathrm{N}$ & Media & ds \\
\hline \multirow[t]{2}{*}{ M } & Dientes cariados & 9 & 5,56 & 3,21 & 20 & 5,05 & 2,87 & 19 & 6,00 & 3,90 \\
\hline & Caries en boca & 9 & 5,78 & 3,23 & 20 & 5,25 & 2,99 & 19 & 6,37 & 4,41 \\
\hline \multirow[t]{2}{*}{$\mathrm{F}$} & Dientes cariados & 8 & 5,75 & 2,05 & 40 & 6,03 & 3,16 & 21 & 6,10 & 3,73 \\
\hline & Caries en boca & 8 & 6,50 & 2,56 & 40 & 6,33 & 3,38 & 21 & 6,71 & 4,13 \\
\hline \multirow{2}{*}{$\begin{array}{l}\text { Media } \\
\text { Grupal }\end{array}$} & Dientes cariados & 17 & 5,65 & 2,64 & 60 & 5,70 & 3,08 & 40 & 6,05 & 3,76 \\
\hline & Caries en boca & 17 & 6,12 & 2,87 & 60 & 5,97 & 3,27 & 40 & 6,55 & 4,22 \\
\hline
\end{tabular}

* Se consideraron solamente los individuos adultos de sexo determinado. 
caries de superficie lisa (mesial y lingual) son más frecuentes en individuos de Estatus Inferior, pero raramente aparecen en los otros dos grupos. Al ser agrupadas (categorías 3 a 6), las caries extraoclusales son significativamente menos frecuentes en individuos de Estatus Inferior, lo que indicaría, en primera instancia, una dieta menos cariogénica (tal vez más pobre en carbohidratos refinados). De la conjunción de indicadores inferimos que, aunque los individuos de Estatus Bajo tienen una media de caries por individuo más alta, esta no necesariamente refleja el consumo de una dieta más cariogénica. En este sentido, individuos de Estatus Medio a pesar de tener menos caries en media, consumen una dieta relativamente más cariogénica (probablemente asociada a un mayor acceso a determinados productos dietéticos, inclusive chicha o coca).

Aunque las diferencias intragrupo no son fáciles de distinguir, es notable que los individuos de Los Pinos comparten un patrón de distribución de caries relativamente homogéneo, ya detectado en poblaciones andinas prehispánicas tardías (Godoy 2005; Pezo-Lanfranco 2010), caracterizado principalmente por la elevada frecuencia de caries cervicales en el sector posterior del maxilar y de la mandíbula y remanentes radiculares, más comunes en el sector posterior del maxilar (Figura 4). Ambos tipos de caries, relacionados al consumo de una dieta extremamente cariogénica, caracterizan el patrón de patología oral de Los Pinos.

\section{Análisis de Prevalencia}

El análisis de prevalencia (Tabla 6), que evalúa la presencia de condiciones patológicas en los individuos de una población, muestra que con excepción de las caries, cuya prevalencia es menor en individuos de Estatus Superior (76\%, frente a una prevalencia de $92 \%$ en los otros dos grupos, estadísticamente significativa al ser comparada con Estatus Medio $X^{2}=4,4757 p=0,0344 ;$ Fisher $=0,0657$ ), no hay diferencias significativas para el resto de indicadores.

En la evaluación intergrupal por sexos se observa que casi la totalidad de individuos masculinos y femeninos está afectada por caries, sin diferencias significativas. Las comparaciones tampoco muestran diferencias significativas para las otras variables evaluadas.

Por tratarse de procesos crónicos, las lesiones orales pueden incrementarse con la edad de los individuos. En Los Pinos, la caries afecta a todos los grupos etarios sin una tendencia clara al incremento con la edad. Por el contrario, esta tendencia es más clara para AMTL, lesiones periapicales y enfermedad periodontal, más prevalentes a medida que la edad avanza. Sin embargo, sin diferencias significativas en las comparaciones intra o intergrupales. Debido al menor tiempo de exposición a los agentes cariogénicos, pocos subadultos están afectados por caries y ninguno sufrió de AMTL, enfermedad periodontal o lesiones periapicales.

\section{Indicadores periodontales}

La prevalencia de enfermedad periodontal (periodontitis), varía aproximadamente entre 60 y $80 \%$ de todos los individuos adultos. Es algo mayor en el grupo de Estatus Superior y menor en individuos de Estatus Medio, sin diferencias significativas intragrupo o intergrupo. En general, los individuos de Los Pinos muestran una considerable cantidad de cálculo dental y reabsorción alveolar, que debe estar asociada al consumo de mayor cantidad de almidones en la dieta, formas de preparación y consumo (por refinado y gelatinización) y precarios hábitos de higiene (Carranza 1986; Lindhe 1999). No obstante, estos índices (Tabla 7) no muestran diferencias significativas entre sus valores promedio (ANOVA Cálculo dental: $F=1,674 p=0,199$; Reabsorción alveolar: $F=0,090 p=0,914$ ).

Los indicadores de masticación de hoja de coca (según criterios de Indriati y Buikstra 2001) mostraron una tendencia similar entre grupos (Tabla 8). Aproximadamente entre uno y dos tercios de los individuos tienen un patrón de lesión compatible con el hábito de coqueo. En las comparaciones intragrupo (masculinos vs femeninos) se observa el predomino de individuos masculinos con indicadores del hábito sobre individuos femeninos en todos los grupos de estatus, pero sin diferencias significativas (Estatus Superior: $X^{2}=1,4462 p=0,2291$; Estatus Medio: $X^{2}=0,3971 p=0,5286$; Estatus Inferior: $X^{2}=0,3275 p=0,7451$ ).

En las comparaciones intergrupo, vemos que en el grupo de Estatus Superior hay una mayor proporción de individuos masculinos $(66,7 \%)$ con signos compatibles con el hábito, pero sin diferencias estadísticamente significativas cuando son comparados con individuos de Estatus Medio $\left(X^{2}=0,6971 p=0,4038\right)$ y Estatus Inferior $\left(X^{2}=\right.$ $1,4237 p=0,2248)$, entre los que tampoco hay diferencias. En individuos femeninos, aunque la 

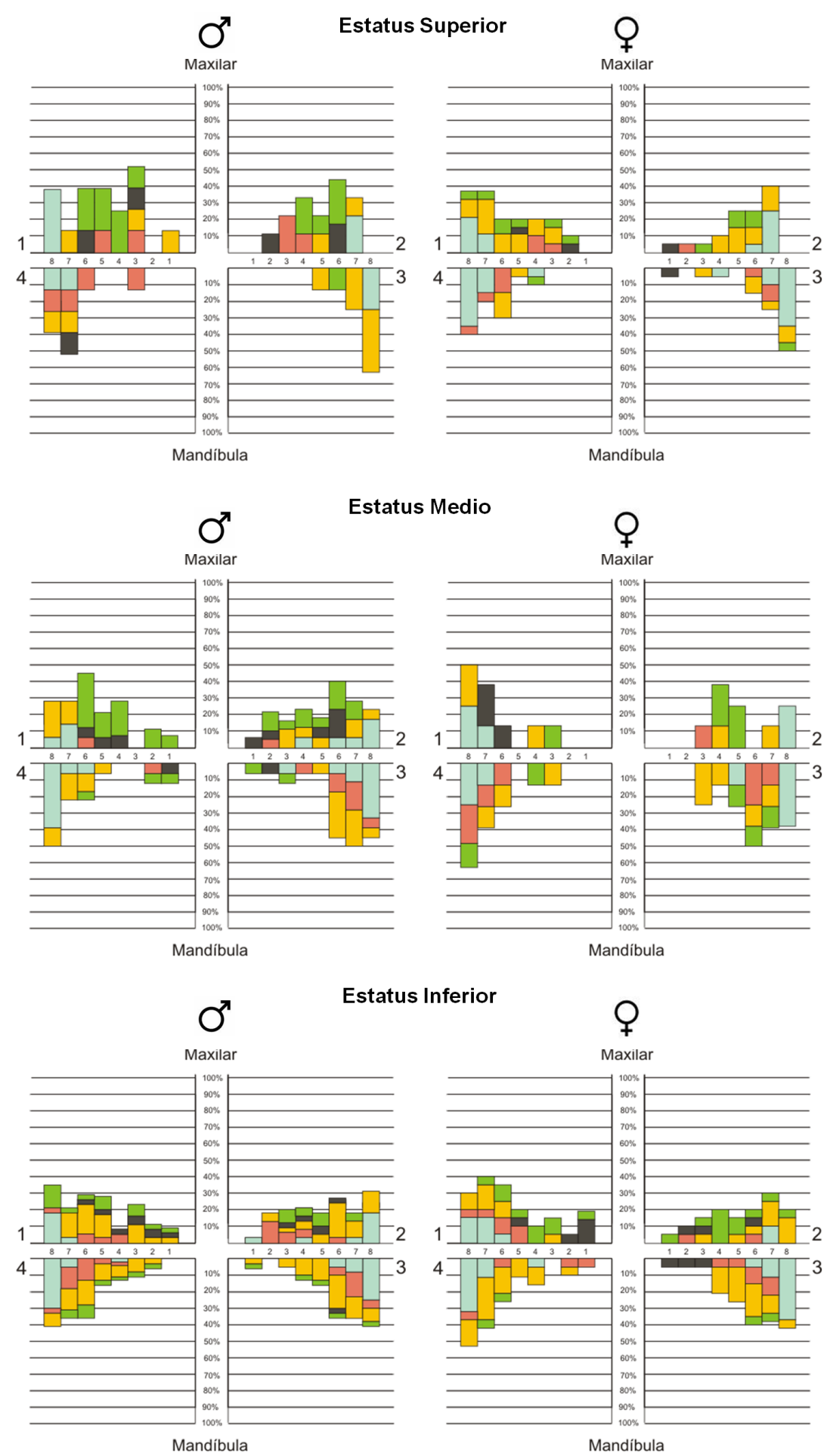

$\square$ Caries oclusales $\square$ Caries Extra-oclusales $\square$ Caries cervicales CEJ

Desgaste, exposición pulpar y caries $\square$ Remanentes radiculares

Figura 4. Distribución de tipos de caries por diente, según sexo y estatus en Los Pinos. Caries types distribution by tooth, sex and status in Los Pinos. 
Tabla 6. Prevalencia de patologías orales según estatus, sexo y edad*. Prevalence of oral pathologies by status, sex and age.

\begin{tabular}{|c|c|c|c|c|c|c|c|c|c|c|c|}
\hline Estatus & Sexo & Edad & $\mathrm{N}$ & Caries & $\%$ & AMTL & $\%$ & Perio & $\%$ & LPx & $\%$ \\
\hline \multirow{12}{*}{ Superior } & \multirow{3}{*}{ M } & $\mathrm{AJ}$ & 1 & 1 & 100,0 & 0 & 0,0 & 1 & 100,0 & 1 & 100,0 \\
\hline & & $\mathrm{AM}$ & 8 & 8 & 100,0 & 7 & 87,5 & 6 & 75,0 & 6 & 75,0 \\
\hline & & Subtotal & 9 & 9 & 100,0 & 7 & 77,7 & 7 & 77,78 & 7 & 77,78 \\
\hline & \multirow{4}{*}{$\mathrm{F}$} & $\mathrm{AJ}$ & 2 & 2 & 100,0 & 0 & 0,0 & 0 & 0,0 & 0 & 0,0 \\
\hline & & $\mathrm{AM}$ & 4 & 4 & 100,0 & 4 & 100,0 & 4 & 100,0 & 3 & 75,0 \\
\hline & & $\mathrm{AV}$ & 2 & 2 & 100,0 & 2 & 100,0 & 2 & 100,0 & 2 & 100,0 \\
\hline & & Subtotal & 8 & 8 & 100,0 & 6 & 75,0 & 6 & 75,0 & 5 & 62,5 \\
\hline & \multirow{5}{*}{ Ind } & SA & 6 & 0 & 0,0 & 0 & 0,0 & 0 & 0,0 & 0 & 0,0 \\
\hline & & $\mathrm{AJ}$ & 1 & 1 & 100,0 & 1 & 100,0 & 1 & 100,0 & 1 & 100,0 \\
\hline & & $\mathrm{AM}$ & 1 & 1 & 100,0 & 1 & 100,0 & 1 & 100,0 & 1 & 100,0 \\
\hline & & Subtotal & 8 & 2 & 25,0 & 2 & 25,0 & 2 & 25,0 & 2 & 25,0 \\
\hline & & Total & 25 & 19 & 76,00 & 15 & 60,0 & 15 & 60,0 & 14 & 66,0 \\
\hline \multirow{12}{*}{ Medio } & \multirow{4}{*}{ M } & $\mathrm{Ad}$ & 1 & 1 & 100,0 & 0 & 0,0 & 0 & 0,0 & 0 & 0,0 \\
\hline & & $\mathrm{AJ}$ & 7 & 6 & 85,7 & 2 & 28,6 & 3 & 42,9 & 3 & 42,9 \\
\hline & & $\mathrm{AM}$ & 12 & 11 & 91,7 & 9 & 75,0 & 9 & 75,0 & 9 & 75,0 \\
\hline & & Subtotal & 20 & 18 & 90,0 & 11 & 55,0 & 12 & 60,0 & 12 & 60,0 \\
\hline & \multirow{4}{*}{$\mathrm{F}$} & $\mathrm{AJ}$ & 7 & 6 & 85,7 & 3 & 42,9 & 0 & 0,0 & 1 & 14,3 \\
\hline & & $\mathrm{AM}$ & 23 & 23 & 100,0 & 17 & 73,9 & 14 & 60,8 & 16 & 69,3 \\
\hline & & AV & 10 & 9 & 90,0 & 9 & 90,0 & 9 & 90,0 & 7 & 70,0 \\
\hline & & Subtotal & 40 & 38 & 95,0 & 26 & 65,0 & 23 & 57,5 & 24 & 60,0 \\
\hline & \multirow{4}{*}{ Ind } & SA & 3 & 2 & 66,7 & 0 & 0,0 & 0 & 0,0 & 0 & 0,0 \\
\hline & & $\mathrm{AM}$ & 2 & 2 & 100,0 & 2 & 100,0 & 2 & 100,0 & 2 & 100,0 \\
\hline & & Subtotal & 5 & 4 & 80,0 & 2 & 100,0 & 2 & 100,0 & 2 & 100,0 \\
\hline & & Total & 65 & 60 & 92,3 & 42 & 64,6 & 37 & 56,9 & 38 & 58,5 \\
\hline \multirow{16}{*}{ Inferior } & \multirow{5}{*}{ M } & Ad & 1 & 1 & 100,0 & 0 & 0,0 & 0 & 0,0 & 0 & 0,0 \\
\hline & & $\mathrm{AJ}$ & 6 & 6 & 100,0 & 4 & 66,7 & 3 & 50,0 & 5 & 83,3 \\
\hline & & $\mathrm{AM}$ & 11 & 11 & 100,0 & 8 & 72,7 & 9 & 81,8 & 8 & 72,7 \\
\hline & & AV & 1 & 1 & 100,0 & 1 & 100,0 & 1 & 100,0 & 0 & 0,0 \\
\hline & & Subtotal & 19 & 19 & 100,0 & 13 & 68,42 & 13 & 68,42 & 13 & 68,42 \\
\hline & \multirow{6}{*}{$\mathrm{F}$} & SA & 1 & 1 & 100,0 & 0 & 0,0 & 0 & 0,0 & 0 & 0,0 \\
\hline & & $\mathrm{Ad}$ & 4 & 4 & 100,0 & 0 & 0,0 & 0 & 0,0 & 1 & 25,0 \\
\hline & & $\mathrm{AJ}$ & 3 & 3 & 100,0 & 0 & 0,0 & 2 & 66,7 & 1 & 33,3 \\
\hline & & $\mathrm{AM}$ & 12 & 12 & 100,0 & 11 & 91,7 & 10 & 83,3 & 8 & 66,7 \\
\hline & & AV & 1 & 1 & 100,0 & 1 & 100,0 & 1 & 100,0 & 1 & 100,0 \\
\hline & & Subtotal & 21 & 21 & 100,0 & 12 & 57,14 & 13 & 61,90 & 12 & 57,14 \\
\hline & \multirow{5}{*}{ Ind } & SA & 10 & 6 & 60,0 & 0 & 0,0 & 0 & 0,0 & 0 & 0,0 \\
\hline & & Ad & 2 & 2 & 100,0 & 0 & 0,0 & 0 & 0,0 & 0 & 0,0 \\
\hline & & $\mathrm{AM}$ & 3 & 3 & 100,0 & 3 & 100,0 & 1 & 33,3 & 1 & 33,3 \\
\hline & & Subtotal & 15 & 15 & 100,0 & 3 & 20,0 & 1 & 6,7 & 1 & 6,7 \\
\hline & & Total & 55 & 51 & 92,7 & 28 & 50,9 & 27 & 49,1 & 25 & 45,5 \\
\hline
\end{tabular}

* La prevalencia representa el número de individuos afectados por una determinada condición (de cualquier intensidad) en cada grupo. AMTL $=$ Diente perdido antemortem $;$ Perio $=$ Periodontitis $;$ LPX $=$ Lesión periapical. 
Tabla 7. Índices de cálculo dental y reabsorción alveolar según estatus.

Dental calculus index and alveolar resorption index by status.

\begin{tabular}{|c|c|c|c|c|c|c|}
\hline \multirow{2}{*}{ Estatus } & \multirow{2}{*}{ Sexo } & \multirow{2}{*}{$\mathrm{N}$} & \multirow{2}{*}{$\frac{\text { Cálculo dental }}{\text { Media }}$} & \multicolumn{3}{|c|}{ Reabsorción alveolar } \\
\hline & & & & ds & Media & ds \\
\hline \multirow{4}{*}{ Superior } & M & 9 & 2,74 & 0,41 & 1,56 & 0,28 \\
\hline & $\mathrm{F}$ & 8 & 2,82 & 0,30 & 1,75 & 0,64 \\
\hline & Ind & 8 & 1,33 & 1,11 & 0,45 & 0,66 \\
\hline & Media & 25 & 2,32 & 0,96 & 1,27 & 0,78 \\
\hline \multirow{4}{*}{ Medio } & M & 20 & 2,68 & 0,39 & 1,36 & 0,44 \\
\hline & $\mathrm{F}$ & 40 & 2,59 & 0,59 & 1,49 & 0,62 \\
\hline & Ind & 4 & 1,53 & 1,31 & 1,12 & 1,43 \\
\hline & Media & 64 & 2,55 & 0,65 & 1,43 & 0,64 \\
\hline \multirow{4}{*}{ Inferior } & M & 19 & 2,73 & 0,40 & 1,59 & 0,43 \\
\hline & $\mathrm{F}$ & 21 & 2,39 & 0,74 & 1,47 & 0,64 \\
\hline & Ind & 15 & 1,26 & 0,96 & 0,42 & 0,69 \\
\hline & Media & 55 & 2,20 & 0,96 & 1,22 & 0,77 \\
\hline
\end{tabular}

Tabla 8. Hábito de masticado de hoja de coca por sexo según estatus*.

Coca leaf chewing habit by sex and status.

\begin{tabular}{ccccc}
\hline \multirow{2}{*}{ Estatus } & Sexo & \multicolumn{2}{c}{ Compatible } & $\begin{array}{c}\text { Total de } \\
\text { evaluados }\end{array}$ \\
\cline { 3 - 5 } & & $\mathrm{n}$ & $\%$ & \\
\hline \multirow{3}{*}{ Superior } & $\mathrm{M}$ & 6 & 66,7 & 9 \\
& S & 3 & 37,5 & 8 \\
& Subtotal & 9 & 52,9 & 17 \\
\hline \multirow{3}{*}{ Medio } & $\mathrm{M}$ & 10 & 50,0 & 20 \\
& $\mathrm{~F}$ & 17 & 41,5 & 41 \\
& Subtotal & 27 & 41,5 & 61 \\
\hline \multirow{3}{*}{ Inferior } & $\mathrm{M}$ & 8 & 42,1 & 19 \\
& $\mathrm{~F}$ & 7 & 33,3 & 21 \\
& Subtotal & 15 & 37,5 & 40 \\
\cline { 2 - 5 } & Total & 51 & 43,2 & 118
\end{tabular}

* En este análisis solo se consideraron los individuos adultos con sexo determinado.

frecuencia es mayor en el grupo de Estatus Medio $(41,5 \%)$, no hay diferencias significativas con los de Estatus Superior $\left(X^{2}=0,0435 p=0,8347\right)$ y Estatus Inferior $\left(X^{2}=0,3869 p=0,5339\right)$.

\section{Índices de desgaste dental}

El índice de desgaste oclusal es semejante entre grupos (Estatus Superior: media $=4,47 d s=1,68$; $\min =1,0 ;$ máx $=6$; Estatus Medio: media $=4,84$ $d s=1,21 ; \min =1,8 ; \max =7,8$ y Estatus Inferior: media $=4,37 d s=1,47 ; \min =1,0 ;$ máx=6,8), sin diferencias significativas entre los tres grupos (Test Kruskal-Wallis $X^{2}=2,506 p=0,286$ ), y no hay indicios que nos lleven a pensar que dietas de textura distinta estaban siendo consumidas.

La relación edad-desgaste también sigue una tendencia similar entre grupos (Figura 5) y el único hallazgo interesante es el alto índice de desgaste del grupo subadulto de Estatus Inferior en relación con sus pares de Estatus Superior (con diferencias significativas Test Mann Whitney $Z=-2,063$ $p=0,039$ ) y Medio (no significativo), que sugiere el consumo de una dieta menos procesada o con más partículas abrasivas.

\section{Consideraciones sobre la dieta de los diferentes grupos de estatus social de Los Pinos}

Del análisis realizado aquí se desprende que independientemente del grupo de estatus social al cual fueron adscritos, todos los individuos de Los Pinos estaban expuestos a una dieta considerablemente cariogénica, con un patrón de lesiones compartido en el que predominan las lesiones oclusales y una altísima proporción de caries cervicales y remanentes radiculares.

La calidad de las lesiones es compatible con el alto contenido de carbohidratos (sobre todo 


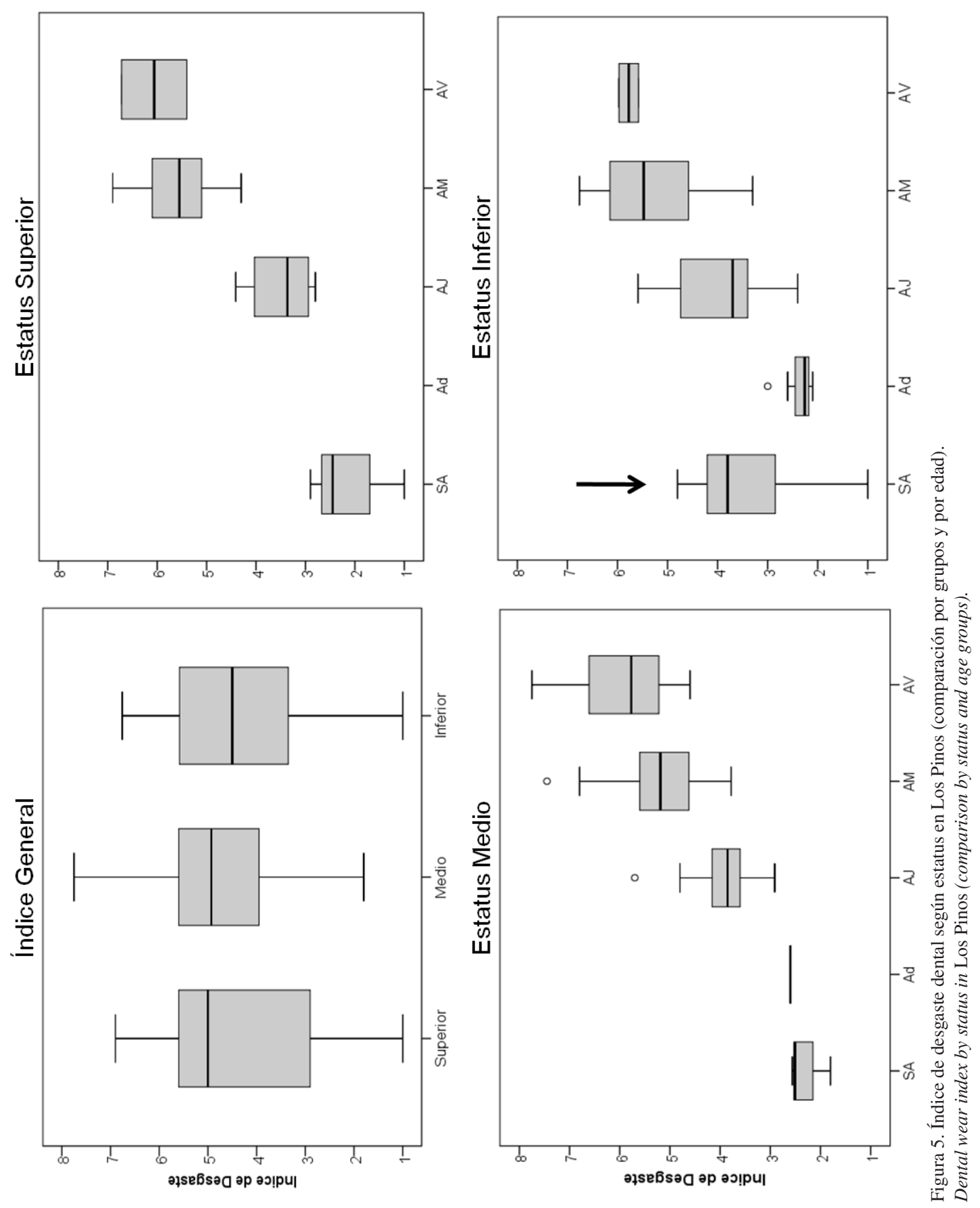


almidones) del inventario dietético y formas de preparación por refinado y cocido a alta temperatura. En Los Pinos, además de maíz, el inventario incluye tubérculos como camote (Ipomoea batatas), papa (Solanum tuberosum), mandioca (Manihot utilissima), que molidos y gelatinizados serían sustrato adecuado para la aparición de caries. Por otro lado, nuestro análisis confirma la importancia de otros dos factores dietéticos característicos de esta época potencialmente dañinos para la salud oral: el coqueo y el consumo de chicha.

Los indicadores de caries sugieren un mayor consumo de carbohidratos en individuos de mayor estatus y que los individuos de Estatus Inferior tienen una dieta menos cariogénica a pesar de tener medias de caries más altas. Esta paradoja está explicada por la localización y tipos de caries, mientras que son mayoritariamente oclusales en individuos de Estatus Inferior, son mayoritariamente extra-oclusales en los otros dos grupos. En este sentido, los subadultos de Estatus Inferior también parecen haber estado más expuestos a dietas muy cariogénicas.

Hay además una mayor propensión a la caries y pérdida dental en mujeres que podría estar relacionada con un mayor consumo de carbohidratos asociado a factores culturales (preferencia por determinados productos, consumo oportunista durante sus actividades cotidianas) o fisiológicos (embarazo, menopausia) (Lukacs y Largaespada 2006) difíciles de elucidar.

Por otro lado y contra lo esperado, en este análisis hay más pérdida dental en mujeres de Estatus Superior y Medio que en las de Estatus Inferior. Las causas son inciertas, pero hipotéticamente las mujeres "pobres" no estaban tan expuestas a los factores que produjeron las AMTL en las mujeres de Estatus Superior y Medio. Considerando el contexto general, la explicación probablemente se encuentre en el consumo diferenciado de chicha o coca. La explicación a la menor prevalencia de AMTL en individuos masculinos de Estatus Medio en relación con los de Estatus Inferior y Superior puede ser estocástica, pero la mayor prevalencia de AMTL en individuos de Estatus Superior podría ser atribuida a una mayor asiduidad del coqueo.

Las AMTL también suelen estar relacionadas con el consumo de alimentos más abrasivos o el uso de los dientes como herramienta, pero en este caso los indicadores apuntan hacia los carbohidratos cariogénicos y/o hábito de coqueo como factores etiológicos.

En el primer escenario, las cantidades expresivas de cálculo dental son evidencia de una dieta rica en carbohidratos de tipo almidón, blanda y de fácil acumulación, y la consecuente enfermedad periodontal desempeñaría un papel bastante importante en la generación de AMTL. Aunque teóricamente haya más enfermedad periodontal y más AMTL en personas pobres y mal nutridas, que tienen mayores probabilidades de estar inmunológicamente comprometidas (Carranza 1986), esta premisa no se confirma en nuestro análisis.

En el segundo escenario, nuestros resultados confirman el carácter extendido del hábito de coqueo sostenido por la etnohistoria para el PIT. Entre 33 y $66 \%$ de los individuos adultos, independientemente de su estatus, tienen indicadores compatibles con el hábito. Mientras las fuentes etnográficas han reportado un mayor consumo de la hoja de coca en hombres, las fuentes etnohistóricas afirman que la coca era consumida por todos los grupos sociales (Espinoza 1987; Indirati y Buikstra 2001; Langsjöen 1996).

En este sentido, nuestros datos indican que el consumo no discrimina entre hombres y mujeres, y aunque podríamos especular un mayor consumo en individuos masculinos (o quizás un inicio más precoz), las diferencias no son categóricas. Según Rostworowski (1993:273), los encargados de cosechar la coca eran ancianos y mujeres jóvenes. Es posible que las mujeres se iniciaran en el consumo de la hoja mientras la cosechaban.

Por otro lado, la mayor proporción de individuos de Estatus Superior con signos del hábito de coqueo puede tener más lógica si consideramos que, por ser un bien de prestigio, la coca cosechada era repartida según el estatus social del individuo (Espinoza 1987:108; Rostworowski 1993, 2004:331). Así, es posible que la práctica del hábito haya sido más extendida entre los individuos de mayor estatus. La coca, que se mastica mezclada con sustancias básicas (como cal, para extraer el alcaloide de la hoja o cenizas de vegetales, para mejorar el sabor) provoca xerostomía y, como consecuencia, severas irritaciones al aparato de soporte del diente (periodontitis) y mayor riesgo de caries (Bradley 
2013; Indirati y Buikstra 2001; Langsjöen 1996). En nuestro análisis estos indicadores también son más frecuentes en individuos de Estatus Superior.

Aparte, el consumo regular de chicha puede ser considerado un factor etiológico importante en la generación de caries. Además de Sacharomyces, la chicha contiene grandes cantidades de Lactobacillus (un microorganismo presente en individuos con mayor riesgo de caries) (Kleinberg 2002; Badet y Thebaud 2008) y tiene un $\mathrm{pH}$ de aproximadamente 3,5-5,4 (Manrique 1979), suficiente para poner un diente en situación de riesgo cariogénico. Además, la receta tradicional de producción de chicha, de la forma en que era preparada en el Intermedio Tardío, consiste en varios períodos alternados de hervido (por sobre $100{ }^{\circ} \mathrm{C}$ durante más de 10 horas) y fermentación (Antúnez de Mayolo 1981; Hayashida 2008; Jennings 2005) que producirían una ruptura de los polisacáridos y mayor facilidad de metabolización por bacterias cariogénicas.

También la cantidad consumida y asiduidad del consumo de chicha podrían explicar algunas diferencias. Según datos etnográficos, a inicios del siglo XX se bebía en los Andes un promedio de 2 a 3 litros de chicha por día (se consumía 6 a 15 litros durante las fiestas), que podría ser similar al escenario del PIT, en que la chicha era bebida inclusive en sustitución del agua (Antúnez de Mayolo 1981:90, 93; Jennings 2005:247).

Hipotéticamente el coqueo produciría una boca alcalina y seca, mucho más dañina para el aparato de soporte que para los dientes, y la chicha una boca ácida, que habría producido cambios ecológicos orales, potencializando el efecto cariogénico de colonias de Actinomyces y Streptococo mutans (Kleinberg 2002; Lingström et al. 2000; Love y Jenkinson 2002). La concomitancia de ambas en episodios alternados produciría un choque ácido que probablemente descalcificaría más rápido superficies menos calcificadas como el cemento (Williams 2006), explicando las altas frecuencias de caries cervical.

Respecto de la abrasividad de la dieta, aunque una cerámica rústica o el molido de vegetales en batanes pudiera haber acarreado abrasivos, en
Los Pinos el desgaste parece estar más asociado a los métodos de procesamiento y conservación de alimentos utilizados en comunidades costeras andinas. Entre estos son tradicionales el almacenaje de pescados, moluscos y vegetales en hoyos cubiertos de arena y el deshidratado de pescado en tendales de suelos salinos o salitrosos.

Aunque es difícil aislar un factor etiológico, la anchoveta (Engraulins ringens) seca y varias especies de moluscos, que pueden haber acarreado arena u otros abrasivos, han sido observadas entre los restos de alimentos (almacenados en vasijas como ofrendas) de Los Pinos. En la localidad de Carquín, a 5 km de Los Pinos, en la misma margen del valle de Huaura, la anchoveta se secaba en tendales de arena durante la época colonial temprana (Antúnez de Mayolo 1981:97). El consumo regular de anchoveta seca-salada podría explicar las diferencias de desgaste observadas en subadultos de Estatus Inferior. Comparada con otros peces más grandes la anchoveta puede ser considerada un recurso de bajo ranking que era más consumida por las clases populares (probablemente también por los niños) desde épocas muy antiguas (PezoLanfranco 2015:533).

En conclusión, los indicadores de patología oral sugieren una dieta más o menos homogénea en Los Pinos, donde el estatus social no parece haber condicionado el consumo diferenciado (al menos cualitativamente) de carbohidratos y posiblemente también de proteínas; sin embargo, estudios isotópicos deben confirmar esta hipótesis. Aunque faltan más datos para entender mejor los efectos particulares del consumo aislado de chicha en los patrones de lesión, definitivamente la coca y la chicha parecen ser los factores claves para explicar el patrón de lesiones observado en Los Pinos y las diferencias entre grupos.

Agradecimientos: Este trabajo fue realizado gracias a Francisco Vallejo, Glenda Pérez, Rosio Gonzáles que facilitaron la realización de los análisis, a los tres revisores anónimos por sus valiosas recomendaciones a FAPESP (Brasil) por el invalorable apoyo económico. 


\section{Referencias Citadas}

Antúnez de Mayolo, S. 1981. La nutrición en el antiguo Perú. Banco Central de Reserva del Perú, Lima.

Badet, C. y N.B. Thebaud 2008. Ecology of lactobacilli in the oral cavity: A review of literature. The Open Microbiology Journal 2:38-48.

Boyce, W.T., P.K.D. Besten, J. Stamperdahl, L. Zhan, Y. Jiang, N.E. Adler y J.D. Featherstone 2010. Social inequalities in childhood dental caries: The convergent roles of stress, bacteria and disadvantage. Social Sciences \& Medicine 71:1644-1652.

Bradley, R. 2013. Coca: An Andean Daily Chew. Cualli Latin American and Iberian Studies Review. Kennesaw State University, Georgia.

Brothwell, D. 1987. Desenterrando Huesos: La Excavación, Tratamiento y Estudio de Restos del Esqueleto Humano. Fondo de Cultura Económica. México D.F.

Brown, L.R., RJ. Billings y A.G. Kaster 1986. Quantitative comparisons of potentially cariogenic microorganisms cultured from noncarious and carious root and coronal tooth surfaces. Infection and Immunity 51:765-770.

Brooks, S.T. y J. Suchey 1990. Skeletal age determination based on the os pubis: A comparison of the Acsádi-Nemeskéri and Suchey-Brooks methods. Human Evolution 5:227-238.

Buikstra, J. y D. Ubelaker 1994. Standards for data collection from human skeletal remains. Archeological Survey Research Series $n^{\circ} 44$. Fayettville, Arkansas.

Cárdenas, M. 1977. Informe preliminar del trabajo de campo del valle de Huaura. Instituto Riva Agüero, Seminario de Arqueología. Pontificia Universidad Católica del Perú, Lima.

Carranza, F. 1986. Periodontología Clínica de Glickman. Editorial Interamericana, México D.F.

Cornejo, M.A. 1991. Patrones funerarios y discusión cronológica en Lauri, Valle de Chancay. En Estudios sobre la Cultura Chancay, Perú, editado por A. Krzanowski, pp. 83-113. Universidad Jaguelona, Crakow.

Dillehay, T. 1987. Estrategias políticas y económicas en las etnias locales del valle del Chillón durante el período prehispánico. Revista Andina 5:407-456.

Espinoza, W. 1987. Artesanos, Transacciones, Monedas y Formas de Pago en el Mundo Andino. Siglos XV y XVI. Banco Central de Reserva del Perú, Lima.

Espinoza, W. 2008. Economía política y doméstica del Tahuantinsuyo. En Compendio de Historia Económica del Perú: Economía Pre-Hispánica I., pp. 315-432. Instituto de Estudios Peruanos - Banco Central de Reserva del Perú, Lima.

Frostell, G., P.H. Keyes y Larson A. 1967. Effect of various sugars and sugar substitutes on dental caries in hamsters and rats. Journal of Nutrition 93:65-73.

Gibbons, R.J., P.F. De Paola, D.M. Spinell y Z. Skobe 1974. Interdental localization of Streptococcus mutans as related to dental caries experience. Infection and Immunity 9:481-488.

Godoy, M.C. 2005. Tiwanaku and Chiribaya: Diet and Dental Diseases during the Middle Horizon and Late Intermediate Period in de Lower Osmore Valley. Dissertation for MSc. in
Dental and Skeletal Bioarchaeology. University College London Institute of Archaeology, London.

Gonzáles, R. 2007. Informe final del Proyecto de Rescate Arqueológico Los Pinos - Huacho. Instituto Nacional de Cultura, Lima.

Hastorf, C. y S. Johannessen 1993. Pre-Hispanic political change and the role of maize in the Central Andes of Peru. American Anthropologist 95:115-38.

Hayashida, F.M. 2008. Ancient beer and modern brewers: Ethnoarchaeological observations of chicha production in two regions of the North Coast of Peru. Journal of Anthropological Archaeology 27:161-174.

Hillson, S.W. 2001. Recording dental caries in archaeological human remains. International Journal of Osteoarchaeology 11:249-289.

Horkheimer, H. 1973. Alimentación y Obtención de Alimentos en el Perú Prehispánico. Universidad Nacional Mayor de San Marcos, Lima.

Indriati, E. y J. Buikstra 2001. Coca chewing in prehistoric coastal Peru: dental evidence. American Journal of Physical Anthropology 114:242-257.

Jennings, J. 2005. La Chichera y el Patrón: Chicha and the Energetics of Feasting in the Prehistoric Andes. En Foundations of Power in the Prehispanic Andes, editado por K.J. Vaughn, D. Ogburn y C.A. Conlee, pp. 241-259. Archeological Papers of the American Anthropological Association Vol. 14 Arlington, Virginia.

Kleinberg I. 2002. A mixed-bacteria ecological approach to understanding the role of the oral bacteria in dental caries causation: An alternative to Streptococcus mutans and the specific-plaque hypothesis. Critical Reviews in Oral Biology and Medicine 13:108-125.

Krzanowski, A. 1991. Influencia Inca en los valles de Huaura y Chancay. En Estudios sobre la Cultura Chancay, Perú, editado por A. Krzanowski, pp. 189-213. Universidad Jaguelona, Crakow.

Langsjöen, O.M. 1996. Dental effects of diet and coca-leaf chewing on two prehistoric cultures of northern Chile. American Journal of Physical Anthropology 101:475-489.

León, E. 2013. 14.000 Años de Alimentación en el Perú. Escuela Profesional de Turismo y Hotelería. Universidad de San Martín de Porres, Lima.

Lingström, P., J. Van Houte y S. Kashket 2000. Food, starches and dental caries. Critical Review in Oral Biology and Medicine 11:366-380.

Lindhe, J. 1999. Tratado de Periodontia Clínica e Implantologia Oral. Guanabara-Koogan, Rio de Janeiro.

Love, R.M. y H.F. Jenkinson 2002. Invasion of dental tubules by oral bacteria. Critical Review in Oral Biology and Medicine 13:171-179.

Lukacs, J.R. 1996. Sex differences in dental caries rates with the origin of Agriculture in South Asia. Current Anthropology $37: 147-153$. 
Lukacs, J.R. y L. Largaespada 2006. Explaining sex differences in dental caries prevalence: saliva, hormones, and "life-history" aetiologies. American Journal of Human Biology 18:540-555.

Manrique, I. 1979. Flora Microbiana de la Chicha de Jora y Fermentación Experimental de Levadura Seleccionada. Tesis de graduación, Programa de Farmacia, Universidad Nacional Mayor de San Marcos, Lima.

Meindl, R. y C.O. Lovejoy 1985. Ectocranial suture closure, a revised method for the determination of skeletal age at death on the lateral anterior sutures. American Journal of Physical Anthropology 68:57-66.

Molnar, S. 1971. Human tooth wear, tooth function and cultural variability. American Journal of Physical Anthropology 34:175-189.

Moore, J.D. 1989. Pre-Hispanic beer in coastal Peru: Technology and social context of prehistoric production. American Anthropologist, New Series 91 (3):682-695.

Murra, JV. 1972. El "control vertical" de un máximo de pisos ecológicos en la economía de las sociedades andinas. En Ortiz de Zúñiga (1562), Tomo II. Universidad Hermilio Valdizán, Huánuco.

Parsons, J. y C. Hastings 1988. The Late Intermediate Period. En Peruvian Prehistory, editado por R. Keatinge, pp. 190-229. Cambridge University Press, Cambridge.

Pattussi, M.P., W. Marcenes, R. Croucher y A. Sheiham 2001. Social deprivation, income inequality, social cohesion and dental caries in Brazilian school children. Social Science \& Medicine 53:915-925.

Pezo-Lanfranco, L. 2010. Reconstrução de Padrões Paleopatológicos Dentais em Agricultores Incipientes e Desenvolvidos do Litoral dos Andes Centrais. Disertación de maestrado, Instituto de Biociências, Universidade de São Paulo, São Paulo.

Pezo-Lanfranco, L. 2015. Intensificação Agrícola $e$ Complexificação Social: Uma Perspectiva Bioarqueológica de Populações Pré-históricas do Litoral dos Andes Centrais. Tesis de doctorado, Instituto de Biociências, Universidade de São Paulo, São Paulo.

Pezo-Lanfranco, L. y S. Eggers 2010. The usefulness of caries frequency, depth, and location in determining cariogenicity and past subsistence: A test on early and later agriculturalists from the Peruvian Coast. American Journal of Physical Anthropology 143:75-91.

Pezo-Lanfranco, L. y S. Eggers 2012. Caries through time: An anthropological overview. En Contemporary approach to Dental Caries, editado por M.-Y. Li, pp. 1-34. Editorial InTech, Rijeka.
Ribeiro, C.C., C.P. Tabchoury, A.A. Del Bel Cury, L.M. Tenuta, P.L. Rosalen y J.A. Cury 2005. Effect of starch on the cariogenic potential of sucrose. Brazilian Journal of Nutrittion 94:44-50.

Rostworowski, M. 1978. Los Señoríos Indígenas de Lima y Canta. Instituto de Estudios Peruanos, Lima.

Rostworowski, M. 1993. Ensayos de Historia Andina: Élites, Etnias, Recursos. Historia Andina 20. Instituto de Estudios Peruanos/Banco Central de Reserva del Perú, Lima.

Rostworowski, M. 2004. Obras Completas III. Historia Andina 26. Instituto de Estudios Peruanos, Lima.

Rugg-Gunn, A.J. y A.F. Hackett 1993. Nutrition and Dental Health. Oxford University Press, Oxford.

Ruiz, A. 1981. Investigaciones arqueológicas en Cerro Colorado. Informe de Avance. Centro de Investigación de Ciencia y Tecnología de Huacho, Huacho.

Sakashita, R., M Inoue, N. Inoue, Q. Pan, H. Zhu 1997. Dental disease in the Chinese Yin-Shang period with respect to relationships between citizens and slaves. American Journal of Physical Anthropology 103:401-408.

Seif, T. y C. Bóveda 1997. Cariología: Prevención, Diagnóstico y Tratamiento Contemporáneo de la Caries Dental. Actualidades Médico Odontológicas Latinoamericanas, Bogotá.

Sheuer, L. y S. Black 2000. Developmental Juvenile Osteology. Academic Press, London.

Silva, J. 1996. Prehistoric Settlement Patterns in the Chillon River Valley, Peru. Doctoral Dissertation, Department of Anthropology, The University of Michigan, Ann Arbor.

Vallejo F. 2008a. Desarrollo y complejización de las sociedades tardías de la Costa central: el caso Ychsma. Arqueología y Sociedad 19:83-114.

Vallejo, F. 2008b. Sistemas funerarios del Intermedio Tardío en la Costa Central peruana: los casos de los cementerios Yschma y Huacho. Presentado en el Simposium Funerary Practices in South America. 2ème Congrès Du Réseau Européen d'Etudes Amérindiennes. Louvain la Neuve, Bélgica.

Walker, P.L. y B.S. Hewlett 1990. Dental health diet and social status among Central African foragers and farmers. American Anthropologist 92:383-398.

Williams, E. 2006. Prevalencia de Caries Coronal y Radicular en Pacientes de la Tercera Edad en Mexicali, Baja California, México. Tesis doctoral, Departamento Estomatología, Universidad de Granada, Granada.

Williams, J.S. y M.A. Katzenberg 2012. Seasonal fluctuations in diet and death during the late horizon: A stable isotopic analysis of hair and nail from the Central Coast of Peru. Journal of Archaeological Science 39:41-57. 